\title{
«Wie weiss mein Körper, wer ich bin?»
}

\author{
Christina Aus der Au
}

Prof. Dr. theol., Mitglied der Redaktion Ethik

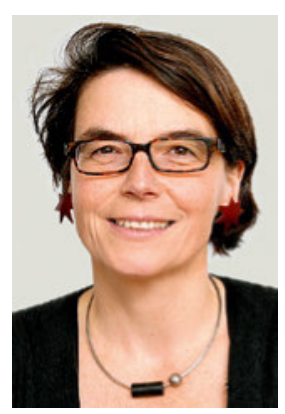

Meine neunjährige Tochter ist im Moment ganz begeistert von einem Gedicht von Robert Gernhardt. Es beginnt mit: «Mein Körper sagt mir, ruh Dich aus!» Das Dichter-Ich stimmt dem gerne zu, schreibt aber dann doch «heimlich dies Gedicht». Und kriegt natürlich prompt Schelte von seinem Körper, was ihn in der letzten Strophe dazu veranlasst, darüber nachzudenken, "wie weiss mein Körper, was ich tu?».

Es ist ein witziges und hintersinniges Gedicht - kein Wunder, dass es meine Tochter bei jeder Gelegenheit mit Vergnügen vorträgt. Und nachdem ich wegen fieser Rückenschmerzen einige Stunden bei der Physiotherapeutin verordnet bekommen habe, geht es auch mir immer mal wieder durch den Kopf: Wie weiss mein Körper, was ich tu? Da drückt mir die liebenswürdige Physiotherapeutin dermassen auf Magen und Unterleib herum, dass ich die Zähne zusammenbeissen muss, um nicht aufzujaulen. Und sie kommentiert dies verständnisvoll mit ... hmmm, jaa, hier der Magen, Stress ... kein Wunder!

Aha, Stress schlägt auf den Magen. Na ja, das weiss ja auch schon die Alltagssprache. Aber es dann so spürbar am eigenen Leib zu erfahren, ist schon noch einmal etwas anderes. Was mich allerdings noch mehr erschreckt, ist die versteckte Befriedigung, mit der ich diese Information aufnehme. Jetzt ist es sozusagen offensichtlich, um nicht zu sagen bewiesen, dass ich gestresst bin. An meinem Körper ist mein Stress medizinisch nachweisbar und nicht mehr bloss eine subjektive Empfindung. Und damit ist es nicht nur für andere glaubwürdiger, sondern auch für mich selber! Jetzt ist es wahr.

Darüber bin ich etwas ins Grübeln gekommen. Warum muss mir mein Körper etwas beweisen, was ich ja eigentlich auch so weiss? Warum sind offenbar mentale Zustände glaubwürdiger, wenn sie sich auch physisch manifestieren?

Dahinter steckt natürlich zum einen die ganze GehirnGeist-Diskussion: Können der Geist und die Empfindungen vollständig physisch-neuronal abgebildet werden? Und was bedeutet das? Es zeigt sich zum andern allerdings auch ein naturalistisches Weltbild, das ich von mir so gar nicht kannte: Es ist der Körper, an dem man letztlich erkennt, was Sache ist. Und das nicht nur für meine Mitmenschen, denen ich damit zeigen könnte: Es ist nicht nur meine Einbildung, sondern schau mal, hier schlägts aus, hier hat die Ärztin, die Physiotherapeutin etwas gefunden! Es ist offenbar auch für mich selber wichtig. Tatsächlich, es ist nicht nur mein Gefühl, sondern es ist wirklich so. Jetzt weiss ich mehr über mich als vorher.

Ist das vielleicht auch ein Grund für all die interessanten Gadgets, Fitnesstracker, Armbänder, Joggingprogramme? Geht es gar nicht unbedingt um die Vergleichbarkeit mit anderen, sondern um die Bestätigung für uns selber? Weil wir uns selber nicht mehr glauben, sondern es schwarz auf weiss haben müssen: Ja, du bist fit; ja, du bist heute 7,5 km gelaufen; ja, du bist gesund. Dagegen kommt kein subjektives Gefühl an! Ich fühle mich ja auch entspannt und gut, wenn ich mich mit einer Tafel Schoggi und einem spannenden Buch aufs Sofa lege. Aber das ist eben nicht gut - gut ist es nur, wenn mir die Zeiger und Zahlen sagen, dass es auch wirklich gut ist! So wie mein Stress auch erst dann wirklich real ist, wenn mein Magen darauf reagiert und ich es auch diagnostiziert kriege.

Ich traue meinem eigenen Gefühl nicht, ich brauche Fakten. Fakten über mich selber, die mir jemand anders liefert. Fakten über mich, um zu wissen, wie es mir geht. Ich bin nicht unmittelbar ich, sondern nur gespiegelt an meinem Körper. Und eben nicht etwa an meinem Leib, der ich bin, den ich selber fühle, spüre, erfahre. Dass das Ich eine leibliche Dimension hat, das haben uns die Phänomenologen und die Feministinnen ja schon vor Jahren aufgezeigt. Aber jetzt geht es nicht mehr nur um meinen Leib, sondern um meinen Körper, den ich habe, der von anderen untersucht, gewogen, vermessen werden kann.

Wahrscheinlich müsste man heute das Gedicht von Gernhardt sogar noch zuspitzen. Bei ihm heisst es zum Schluss: «Die Frage scheint recht schlicht zu sein doch ihre Schlichtheit ist nur Schein! Sie lässt mir seither keine Ruh: Wie weiss mein Körper, was ich tu?» Ich würde also eine weitere Strophe vorschlagen: «Und willst Du gleich aufs Ganze geh'n, so lass die Frage nicht so steh'n. Denn sie ist auch nur der Beginn. Doch sag, wie weiss er, wer ich bin?» 